\title{
Combination Therapy with miR-34a and Doxorubicin Synergistically Induced Apoptosis in T-Cell Acute Lymphoblastic Leukemia Cell Line
}

\section{Shiva Najjary}

Tabriz University of Medical Sciences

Reza Mohammadzadeh

University of Maragheh

\section{Behzad Mansoori}

Tabriz University of Medical Sciences

\section{Fatemeh Vahidian}

Tabriz University of Medical Sciences

\section{Ali Mohammadi}

University of Southern Denmark: Syddansk Universitet

\section{Mohammad Amin Doustvandi}

Tabriz University of Medical Sciences

\section{Vahid Khaze}

Tabriz University of Medical Sciences

Khalil Hajiasgharzadeh

Tabriz University of Medical Sciences

Behzad Baradaran ( $\sim$ baradaranb@tbzmed.ac.ir)

Tabriz University of Medical Sciences https://orcid.org/0000-0002-8642-6795

\section{Research Article}

Keywords: miR-34a, Doxorubicin, Apoptosis, T-cell acute lymphoblastic leukemia (T-ALL)

Posted Date: August 30th, 2021

DOl: https://doi.org/10.21203/rs.3.rs-837119/v1

License: (c) (i) This work is licensed under a Creative Commons Attribution 4.0 International License. Read Full License

Version of Record: A version of this preprint was published at Medical Oncology on October 16th, 2021. See the published version at https://doi.org/10.1007/s12032-021-01578-8. 


\section{Abstract}

Reduced expression of tumor suppressor miRNAs leads to cancer cell development, so restoring the expression of these miRNAs can be an appropriate treatment option for cancer. Due to the heterogeneity of cancer cells, single-drug therapy often results in drug resistance. Therefore, the combination of chemotherapy with miRNA can be a powerful strategy for cancer treatment. In the current investigation, we researched the synergic effect of miR-34a in combination with doxorubicin (DOX) on cell death of acute T-cell lymphoblastic leukemia (T-ALL) Jurkat cell line, as well as the expression of some genes including Caspase-3, Bcl-2, and p53 which are involved in apoptosis. Our outcomes showed that the combination of miR-34a and doxorubicin remarkably reduced the expression of the $\mathrm{Bcl}-2$ gene, the target gene of miR-34a. According to the results of the MTT assay in cells treated with miR-34a and doxorubicin, the survival rate was significantly decreased compared to the untreated cells. Results of the flow cytometry assay and DAPI staining demonstrated an increased apoptosis rate of Jurkat cells in combination therapy. Moreover, cell cycle arrest was observed at the G2/M phase in cells that were treated with miR-34a/doxorubicin. Most importantly, we showed that the transfection of the Jurkat cells with miR-34a increased the sensitivity of these cells to doxorubicin. Furthermore, the combination of miR$34 \mathrm{a}$ and doxorubicin drug effectively increased apoptosis of treated cells. Therefore, this method can be used as an impressive treatment for T-ALL.

\section{Introduction}

T-cell acute lymphoblastic leukemia (T-ALL) is a violent hematologic malignancy that is happening because of the oncogenic conversion of immature T-cell progenitors and is generally represented via the penetration of the bone marrow by malignant lymphoblasts [1]. At the present time, T-ALL accounts for 20-25 percent of adults and 10-15 percent of ALL children [2,3]. Currently, treatment of T-ALL includes high-intensity combination chemotherapy which leads to high survival in children [4]. Unfortunately, chemotherapy has short-term and long-term side effects particularly for young children, the effects of high-dose chemotherapy on the development of bones and the central nervous system should not be ignored $[5,6]$. In addition to side effects, relapse is another important challenge that can be seen in $20 \%$ of children and $40 \%$ of T-ALL adults [7-9]. In recent years, many studies have been conducted to improve the effectiveness of anticancer agents. However, due to drug resistance, most patients especially advanced cancer patients, experience chemotherapy failure [10,11]. Doxorubicin is a cytotoxic drug taken from mutated strains of Streptomyces. Doxorubicin is one of the strongest FDA chemotherapy drugs that offer great therapeutic potential and is an effective treatment for acute lymphoblastic leukemia (ALL) [12]. A study found that treatment with doxorubicin could induce $G 2$ arrest, but essentially no apoptosis in the Jurkat cell line [13]. The discovery of miRNAs has created a new generation for understanding carcinogenesis, especially leukemogenesis $[14,15]$. The emergence of miRNAs as gene expression regulators identifies them as emerging diagnostic and prognostic candidates and potential therapeutic targets [16]. The improper expression of miRNAs can act as an oncogene or tumor suppressor in T-ALL. MiRNAs show a pivotal role in the advancement of T-ALL by regulating cell migration, proliferation, and 
cell death, and chemotherapy resistance through targeting major signaling pathways or transcription factors [14]. Several studies have examined the expression of microRNAs in T-ALL. The results demonstrated that ten miRNAs were highly expressed, including miR-223, miR-19b, miR-20a, miR-92, miR142-3p, miR-150, miR-93, miR-26a, miR-16, and miR-342. In addition, the analysis of 3' UTRs of tumor suppressor genes indicated that five of these highly expressed miRNAs ranked highest in this analysis (miR-19b, miR-26a, miR-92, miR-20a / 93, and miR-223) [17]. In another study, Renou et al. evaluated the expression patterns of 738 miRNAs in pediatric T-ALLs using high-throughput real-time quantitative polymerase chain reaction (R-Q-PCR) analysis. They illustrated that the expression of two clustered miRNAs, miR-125b/99a, increased and reached the peaks in primitive T cells and was also upregulated in the T leukemia homeobox 3 (TLX3) subtype of T-ALL [18]. Moreover, in another study, Wallaert et al. indicated novel miRNAs with extremely high expression levels in various T-ALL patient samples using small RNA-sequencing: hsa-miR-181b-5p (acute myeloid leukemia (AML)), hsa-miR-423-3p, hsa-miR-486$5 p$ (down syndrome myeloid leukemias), and hsa-miR-92b-3p (TLX1/3 T-ALL) [19]. Family members of the miR-34 include three processed miRs that are encoded by two distinct genes: miR-34a is encoded with its own transcript, whilst miR-34b and miR-34c share common transcripts [20]. MiR-34a is a tumor suppressor with reduced expression levels in many cancers [21]. MiR-34a inhibits tumor growth by inhibiting various cellular processes in cancer, including epithelial-to-mesenchymal transition (EMT), cell cycle, metastasis, and inducing apoptosis. MiR-34a regulates these processes by reducing the expression of target mRNAs [22]. In latest years, many experiments have been conducted on the combination of miRNA-based therapeutics and chemotherapy in the treatment of cancers [23]. MiR-34a has been analyzed in combination with various chemotherapy drugs to expand the apoptosis of tumor cells as well as to reduce tumor growth and proliferation [20]. A study by Chao and colleagues showed that the combination of Doxorubicin/Sorafenib or miRNA-34a synergistically suppresses the growth of $143 \mathrm{~B}$ osteosarcoma cells [24]. In another study by Qing et al., MiR-34 mimic caused apoptosis and sensitivity of pancreatic cancer cells to Gemcitabine [25]. Moreover, a study by Marques et al., indicated that miR34a overexpression increases response to doxorubicin in diffuse large B-cell lymphoma (DLBCL) [26]. According to the studies and their results as well as the analyzes performed, the Jurkat cell line was selected for this study. To date, no study has been conducted on the antitumor effect of the combination therapy with miR-34a and doxorubicin in T-ALL, Jurkat cell line. Therefore, in this study, we investigated the effect of the combination of doxorubicin and miR-34a on growth inhibition and induction of apoptosis on T-cell acute lymphoblastic leukemia (T-ALL), Jurkat cell line.

\section{Materials And Methods}

\section{Cell culture}

The human Jurkat cell line was purchased from Pasteur Institute of Iran (IPI) and cultured in RPMI-1640 containing 10 percent fetal bovine serum (FBS) with penicillin plus streptomycin (Gibco, USA). The cells were then incubated at $37^{\circ} \mathrm{C}, 5 \% \mathrm{CO} 2$ humidified incubator. In order to promote efficiency and obtain comparable results, all experiments were conducted in triplicate. 


\section{Transfection of miR-34a mimic}

Jurkat cells were seeded in the six-well plate at $8 \times 10^{5}$ cells/wells with a completed RPMI-1640 medium. Then, miR-34a mimic with the structure of 5囚- UGGCAGUGUCUUAGCUGGUUGU-3》, purchased from Microcynth (Balgach, Switzerland) was transfected using jetPEI according to the constructor protocol (PolyPlus-transfection, Strasbourg, France). Controls for miR-34a mimic and PEl were also included. In brief, $200 \mu \mathrm{l}$ of buffer, concentrations of 1,5 , and $10 \mathrm{nmol}$ of miR-34a and $4 \mu \mathrm{l}$ of jetPEl were added to microtubes, then kept for 15 minutes at room temperature. After 15 minutes, the solution was added to cells in every well and incubated at $37^{\circ} \mathrm{C}$ for $24 \mathrm{~h}$.

\section{Quantitative real-time PCR (qRT-PCR)}

Total RNA was extracted from treated and non-treated Jurkat cells by using RiboEx reagent (GENEALL Biotechnology, Seoul, Korea) pursuant to the manufacturer's guidelines. Then, the purity and concentration of extracted RNA were assessed by Nanodrop 2000C. The complementary DNA (cDNA) was synthesized applying the miScript II RT Kit for miRNA (QIAGEN, Hilden, Germany) and genes (BIOFACT, Korea) based on the manufacturer's protocol. The expression of miRNA and mRNAs was determined according to quantitative RT-PCR (qRT-PCR) assay using miScript SYBR Green PCR Kit (QIAGEN, Hilden, Germany). GAPDH was used as a housekeeping gene for Caspase-3, Bcl-2, and p53, and also the U6 was used as the internal control for miRNA. The primer sequences are according to Table 1. The ratio of expression of each gene was calculated using the Pfaffle (2- $\Delta \Delta \mathrm{CT})$ method. In order to promote efficiency and obtain comparable results, all experiments were conducted in triplicate.

Table 1

Primer sequences in qRT-PCR.

\begin{tabular}{|c|c|c|}
\hline Target gene & Strand & Primer sequence \\
\hline miR-34a & Target sequence & 5囚- UGGCAGUGUCUUAGCUGGUUGU-3》 \\
\hline \multirow[t]{2}{*}{ U6 } & Forward & 5囚- CTTCGGCAGCACATATACTAAAATTGG - 3区 \\
\hline & Reverse & 5囚-TCATCCTTGCGCAGGGG - 3】 \\
\hline \multirow[t]{2}{*}{ GAPDH } & Forward & 5囚- CAAGATCATCACCAATGCCT - 3】 \\
\hline & Reverse & 5囚- CCCATCACGCCACAGTTTCC - 3囚 \\
\hline \multirow[t]{2}{*}{ Caspase-3 } & Forward & 5囚-TGTCATCTCGCTCTGGTACG - 3囚 \\
\hline & Reverse & 5囚- АAATGACCCCTTCATCACCA - 3】 \\
\hline \multirow[t]{2}{*}{$B c /-2$} & Forward & 5囚- CCTGTGGATGACTGAGTACC - 3® \\
\hline & Reverse & 5囚- GAGACAGCCAGGAGAAATCA - 3® \\
\hline \multirow[t]{2}{*}{$p 53$} & Forward & 5囚- CGTCCAGGGAGCAGGTAG - 3】 \\
\hline & Reverse & 5囚- AAGTAGTTTCCATAGGTCTGA - 3】 \\
\hline
\end{tabular}




\section{Cell viability assay}

The toxicity of miR-34a and doxorubicin on Jurkat cells was determined using a cell viability assay. In brief, cells were treated with miR-34a and doxorubicin either alone or in combinations for $72 \mathrm{~h}$. After $72 \mathrm{~h}$ of incubation, the cells in each well were treated with the concentration of $20 \mu$ of MTT (Sigma-Aldrich, USA, $5 \mathrm{mg} / \mathrm{ml}$ dissolved in PBS) and incubated for $4 \mathrm{~h}$ at $37^{\circ} \mathrm{C}$. After removing the supernatant of each well, $200 \mu$ of DMSO was added and gently shacked. The absorbance for each well was measured at $570 \mathrm{~nm}$ by a spectrophotometer. The ratio of cell survival was calculated based on the subsequent equation:

$\%$ viable cells $=\frac{\text { absorbanceofsample }}{\text { absorbanceofcontrol }} \times 100$

\section{Apoptosis assay}

To determine the apoptosis rate after all treatments, we performed a flow cytometry analysis using an annexin V-FITC staining kit. In brief, $8 \times 10^{5}$ cells per well were seeded into a six-well plate then treated with miR-34a and doxorubicin either alone or in combinations for $72 \mathrm{~h}$. An annexin V-FITC staining kit (Exbio, Czech Republic) was applied to stain the apoptotic cells as described by the manufacturer's instructions. After washing with cold PBS, cells were incubated with Annexin V-FITC and propidium iodide (Exbio, Czech Republic) at room temperature in the dark for $15 \mathrm{~min}$. The results were determined by using flow cytometry.

\section{DAPI staining}

For imaging of fixed cells, $8 \times 10^{5}$ cells per well were seeded into a six-well plate then treated with miR$34 \mathrm{a}$ and doxorubicin either alone or in combinations for $72 \mathrm{~h}$. After $72 \mathrm{~h}$ of incubation, cells were treated with $4 \%$ paraformaldehyde then washed with PBS. These cells were then treated with $0.1 \%$ of Triton X100 , followed by another wash with PBS. After that, cells were stained with DAPI (4',6-diamidino-2phenylindole) and incubated at room temperature for $10 \mathrm{~min}$. The DAPI-stained cells were then detected by fluorescence microscopy.

\section{Cell cycle analysis}

This assay was done to distinguish various stages of the cell cycle. In brief, $8 \times 10^{5}$ cells per well were seeded into a six-well plate then treated with miR-34a and doxorubicin either alone or in combinations for $72 \mathrm{~h}$. After $24 \mathrm{~h}$, cells were added into microtube, washed with PBS, and after that fixed with cold $70 \%$ ethanol for 48h at -20. After that, 500 $\mu$ PBS and 5 $\mu$ l RNase A (Pishgam, Iran) were added, incubated for half an hour. Next, $1 \mathrm{ml}$ Tris (100X) (AppliChem, Germany) mixed with 100ml PI (Exbio, Czech Republic) solution $(0.5 \mu \mathrm{l})$ was added to Jurkat cells. Finally, cells were incubated in a dark place for $10 \mathrm{~min}$ at room temperature and cell cycle arrest was checked out through flow cytometry MACSQuant 10 (Miltiny biotech, Germany).

\section{Combination effect}


The analysis of the miR-34a combination and doxorubicin was performed to investigate the interaction between this $\mathrm{miR}$ and the anti-cancer drug, doxorubicin. The $\mathrm{Cl}$ results, also known as the combination index, in Jurkat cells was assessed through the subsequent formula: $\mathrm{Cl}=\left[\mathrm{D}_{1} /(\mathrm{Dx})_{1}\right]+\left[\mathrm{D}_{2} /(\mathrm{Dx})_{2}\right]+$ $\left[D_{1} D_{2} /(D x)_{1}(D x)_{2}\right]$. $D_{1}$ and $D_{2}$ are the respective combination doses of miR-34a and drugs that yield an effect of $50 \%$ growth inhibition, with $(\mathrm{Dx})_{1}$ and $(\mathrm{Dx})_{2}$ being the corresponding single doses for miR-34a and drug. As a result, there are three types of $\mathrm{Cl}$ including $\mathrm{Cl}<1$ (synergism), $\mathrm{Cl}=1$ (summation), and $\mathrm{Cl}>$ 1 (antagonism).

\section{Statistical analysis}

All values are displayed as mean \pm SD. GraphPad Prism 6 software was applied for statistical analysis. One-way and two-way analyses of variance were used to demonstrate statistical differences between two or more groups, followed by Sidak and Tukey tests. Statistically significant differences were considered at $\mathrm{P}<0.05$.

\section{Results}

\section{Transfection of miR-34a showed increased levels of miR- $34 a$ in Jurkat cells}

The expression of miR-34a in Jurkat cells after transfection by miR-34a mimics was determined using qRT-PCR. The Jurkat cells were divided into 4 groups: control group, second group (transfected by $1 \mathrm{nmol}$ of miR-34a), third group (transfected by $5 \mathrm{nmol}$ of miR-34), and fourth group (transfected by $10 \mathrm{nmol}$ of miR-34a). Then, the cells were seeded into a 96-well plate and transfected by miR-34a. The results of the study revealed that the expression quantity of miR-34a was increased significantly in cells transfected by miR-34a compared to the control group (Fig. 1). According to the results, at different concentrations, by increasing the concentration of miR-34a (A), its expression increased compared to the control group. Also, at different times, by increasing the time of transfection (B), the level of miR-34a (at the concentration of $5 \mathrm{nmol}$, which was selected as the best concentration for miR-34a) increased compared to the control group. U6 was used as an internal control.

Synergistic effects of miR-34a and doxorubicin on the expression quantities of Caspase-3, Bcl-2, and p53 genes in Jurkat cells

The effects of the combination of miR-34a and doxorubicin on the expression quantities of Caspase-3, $\mathrm{Bcl}-2$, and p53 genes in the Jurkat cell line were investigated by qRT-PCR. The Jurkat cells were transfected with $5 \mathrm{nmol}$ of miR-34a and treated with an $\mathrm{IC}_{50}$ dose of doxorubicin for $72 \mathrm{~h}$. In this test, U6 was used as an internal control of the microRNA and GAPDH as an internal control of the Bcl-2, a potential target gene of miR-34a, and two other genes including Caspase-3 and p53, which were used to detect the response to the treatment. The results showed that the expression of the Bcl- 2 gene in cells 
treated with the combination of miR-34a/doxorubicin was decreased significantly compared to the control group (Fig. 2). These results were statistically significant $(p<0.00001)$.

\section{Synergistic effects of miR-34a and doxorubicin drug on Jurkat cells viability}

To examine the synergistic results of miR-34a and doxorubicin drug on Jurkat cells viability, an MTT assay was performed. The Jurkat cells were transfected and treated in three groups, the first group was transfected with miR-34a alone at the concentration of $5 \mathrm{nmol}$ for $72 \mathrm{~h}$, the second group was treated with different doses of doxorubicin drug for $72 \mathrm{~h}$, and the third group was treated with the combination of miR$34 \mathrm{a}$ (at the concentration of $5 \mathrm{nmol}$ ) and Dox. The measurements were carried out $72 \mathrm{~h}$ after transfection. The analysis of data demonstrated that reduction in cell viability by transfection of miR-34a alone was dose-dependent. Furthermore, the $\mathrm{IC}_{50}$ value for doxorubicin alone $\left(\mathrm{IC}_{50}=308.5 \mathrm{ng} / \mathrm{ml}\right)$ was determined using the same test. The result of the combination therapy showed that the cell survival rate in the cells treated with the combined miR-34a/doxorubicin drug was meaningfully reduced compared to the control group (Fig. 3). According to the data obtained from the combination of miR-34a and doxorubicin drug and the single-dose data of miR-34a and doxorubicin, we performed the calculations using the $\mathrm{Cl}$ formula. Our results showed that the calculated $\mathrm{Cl}$ values were $\mathrm{Cl}<1$.

\section{Synergistic results of miR-34a and doxorubicin drug on Jurkat cells apoptosis}

To examine the synergistic effects of miR-34a and doxorubicin drug on Jurkat cells apoptosis, a flow cytometry assay was exploited to measure the percentage of apoptotic cells. The Jurkat cells were transfected and treated with miR-34a (at the concentration of $5 \mathrm{nmol}$ ) and treated with an $\mathrm{IC}_{50}$ dose of doxorubicin $(308.5 \mathrm{ng} / \mathrm{ml})$ for $72 \mathrm{~h}$. The results of the flow cytometry demonstrated that the apoptosis in cells that were treated with the combined miR-34a/doxorubicin drug was significantly increased (31.62 \pm 2.6) in comparison with the control group, which confirmed the results of the MTT assay (Fig. 4). Furthermore, DAPI staining was used to analyze nucleus deformation and fragmentation. The results were examined under a fluorescence microscope and presented that the combination of miR-34a and doxorubicin led to nucleus deformation and fragmentation during which occur during apoptosis compared to the control group. Also, the apoptosis rate in the cells treated with the combination of miR34a and doxorubicin was higher than in cells treated with miR-34a alone and drug alone (Fig. 5).

\section{Synergistic results of miR-34a and doxorubicin on cell cycle analysis}

To assess the synergistic effects of miR-34a and doxorubicin on cell cycle regulation and for the elucidation of cell cycle arrest, cell cycle analysis was carried out in Jurkat cells stained with DAPI using flow cytometry. The Jurkat cells were treated with the combination of miR-34a (at the concentration of 
$5 \mathrm{nmol})$ and doxorubicin ( $\mathrm{IC}_{50}$ dose) for $72 \mathrm{~h}$. The results of this test showed that the amount of cell fraction in $G 2$ phases was increased in doxorubicin significantly ( $P$ value $<0.01)$ besides there is more significance cell cycle arrest in sub G1 $(P$ value $<0.01)$ and G2 $(P$ value $<0.05)$ phases in the combined group compared to the control group (Fig. 6).

\section{Discussion}

Acute lymphoblastic leukemia (ALL) is the greatest ordinary malignancy in children. In combined chemotherapy, the disease outcomes for patients with ALL have been significantly improved, but $20 \%$ of the children still die from the disease, and this amount reaches $50 \%$ in adults $[27,28]$. The aberrant expression and function of miRNAs in many human diseases represent them as a therapeutic tool [29]. MiRNAs are dysregulated in nearly all solid cancers and blood malignancies. The development of new treatments has significantly contributed to increasing survival and reducing overall mortality. However, although the classification of cancers has become diverse, the variety and specificity of treatment options are backward [30]. The complexity of miRNA biology offers a new mechanism for treatment intervention but creates specific challenges for the development of therapeutic goals as a medicine. There are two methods for regulating the expression of miRNAs in cancer, the first method is to inhibit the expression of oncogenic miRNAs using synthetic anti-miRNAs, or miRNA antagonists, or Locked nucleic acids (LNAs). The second method is to restore the expression of miRNAs that act as a tumor suppressor, in which case the microRNA replacement therapy is used [31]. MiR-34a is known as a tumor suppressor microRNA and the reduction of its expression has been shown in various studies. As an example, in a study by Ogawa et al., a reduction in the expression quantity of miR-34a in resistant cells to cisdiamminedichloroplatinum in squamous cell carcinoma has been reported [32]. The results of the present study showed that the transfection of miR-34a into cancer cells enhanced their sensitivity to doxorubicin and prevented the growth and proliferation of these cells. In addition, flow cytometry was done to determine the percentage of apoptotic cells, and the results displayed that the apoptosis rate was higher in cells treated with the combination of miR-34a/doxorubicin compared to control as well as single treatments (miR-34a and doxorubicin alone). DAPI staining also displayed a dramatic increase in cell death and nuclear fragmentation in cells treated with the combination of miR-34a/doxorubicin. Moreover, our results demonstrated that the combination of miR-34a/doxorubicin synergistically induced apoptosis in T-ALL and according to cell cycle analysis, inhibition in the G1 phase is consistent with the results of apoptosis. Lee and colleagues also demonstrated that the expression of miR-34a in the MCF-7 cell line of breast cancer (BC), had the ability to restore sensitivity to Adriamycin drug and this effect was reversed by miR-34a inhibitor [33]. Similarly, in a study by Wang and colleagues, miR-34a transfection increased the sensitivity of cells to cisplatin drug in lung cancer [34]. According to studies, miR-34a has been shown to inhibit tumor growth by regulating oncogenes [21]. Caspases are important intermediaries for cell death. Caspase-3 is a cellular death protease that is often active and causes the breakdown of important cellular proteins. Moreover, it is essential for certain processes that are associated with the formation of apoptotic bodies. In a study, the scan of the primary tumor samples in patients undergoing breast surgery showed that approximately $75 \%$ of tumors do not express the Caspase- 3 protein. But, in another study, an 
increase in the expression of Caspase-3 in the breast tumor has been observed [35]. The cause of the contradiction in the results is Caspase-3s, which is the anti-apoptotic variant of the Caspase-3 gene, and its simultaneous expression with Caspase- 3 has been observed in various tumor cells, such as breast cancer. Here, we showed that the expression level of the Caspase 3 gene was increased in combination therapy. Higher expression of Caspase-3 in T-ALL has also been studied in comparison with normal peripheral blood lymphocytes. According to studies, the expression of Caspase- 3 in breast and prostate cancer is associated with tumor progression [36]. Bcl-2 family are the prominent regulators of the apoptotic phase that comprise anti and proapoptotic members where the stability of comparative levels of these antagonists is of the utmost importance for the cells. The role of pro-and anti-apoptotic proteins can change the importance of increased expression of $\mathrm{Bcl}-2$ in human disease. Aberrant expression of $\mathrm{Bcl}-2$ has been observed in a variety of solid tumors such as prostate cancer, breast cancer, and intestinal cancer. In addition, overexpression of $\mathrm{Bcl}-2$ has been reported in ovarian cancers, neuroblastoma, bladder, intestine, head and neck cancers, and small cell lung cancer [37, 38]. In this study, the results of qRT-PCR showed that the expression of Bcl-2, a potential target gene of miR-34a, was decreased in the Jurkat cell line after combination therapy. Tumor suppressor P53 is overtly detectable in the nucleus of ordinary cells. During cellular stress caused by DNA damage, it can stop the advancement of the cell cycle and lead to apoptosis. We also showed in the current study that P53 expression was increased in combination therapy compared to the control group and induced apoptosis. P53 mutations have been observed to be the most common genetic occurrence in human cancers, including colon cancer, breast, and stomach [39]. In a study by Zenz et al., it was found that reduced expression quantity of miR-34a in CLL was connected with P53 mutations, Fludarabine-resistant disease, a disorder in DNA damage response, and apoptosis reduction [40]. Also, Mraz and colleagues realized that the expression quantity of miR-34a in the CLL was continuously decreased with p53 mutations, implying that the recognition of miR-34a expression could be used as a prognostic and diagnostic biomarker for treatment response [41].

\section{Conclusion}

In this research study, the outcomes indicated that miR-34a reduced viability and increased apoptosis in the Jurkat cell line. In addition, in the cells transfected with miR-34a, the sensitivity of cells to doxorubicin was significantly increased compared to the drug alone, which is justifiable by increased apoptosis in transfected cells. So, miR34a and doxorubicin have a synergistic effect in proliferation inhibition and apoptosis induction in cancer cells.

\section{Declarations}

\section{Funding}

This research did not receive any specific grant from funding agencies in the public, commercial, or notfor-profit sectors.

\section{Acknowledgements}


We thank the research staff at the Immunology Research Center, Tabriz University of Medical Sciences for assistance in performing experiments.

\section{Conflicts of interest/Competing interests}

The authors have no conflicts of interest to declare.

\section{Availability of data and material}

The data that support the findings of this study are available from the corresponding author upon reasonable request.

\section{Authors' contributions}

SN, and BB devised the main conceptual ideas and participated in the design of the work. BB provided biological materials and reagents. SN, BM, FV, AM, and MAD performed the experiments. SN, and KH wrote the initial draft of the manuscript. SN, BM, VK, and RM participated in the analysis of the work and reviewed and edited the manuscript. BB, and RM supervised the study.

\section{Ethics approval}

All experiments and procedures were conducted in compliance with the ethical principles of Tabriz University of Medical Science, Tabriz, Iran and approved by the regional ethical committee for medical research.

\section{Consent to participate}

This article does not contain any studies with human or animal subjects performed by any of the authors.

\section{Consent for publication}

All authors agree with publication.

\section{References}

1. Drobna M, Szarzyńska-Zawadzka B, Dawidowska M. T-cell acute lymphoblastic leukemia from miRNA perspective: Basic concepts, experimental approaches, and potential biomarkers. Blood Rev. 2018;32:457-72.

2. Hunger SP, Mullighan CG. Acute Lymphoblastic Leukemia in Children. Longo DL, editor. N Engl J Med. 2015;373:1541-52.

3. Litzow MR, Ferrando AA. How I treat T-cell acute lymphoblastic leukemia in adults. Blood. 2015;126:833-41.

4. Hunger SP, Lu X, Devidas M, Camitta BM, Gaynon PS, Winick NJ, et al. Improved Survival for Children and Adolescents With Acute Lymphoblastic Leukemia Between 1990 and 2005: A Report From the 
Children's Oncology Group. J Clin Oncol. 2012;30:1663-9.

5. Karami H, Baradaran B, Esfahani A, Estiar MA, Naghavi-Behzad M, Sakhinia M, et al. siRNA-mediated Silencing of Survivin Inhibits Proliferation and Enhances Etoposide Chemosensitivity in Acute Myeloid Leukemia Cells. Asian Pacific J Cancer Prev. 2013;14:7719-24.

6. Aghaee F, Pirayesh Islamian J, Baradaran B. Enhanced Radiosensitivity and Chemosensitivity of Breast Cancer Cells by 2-Deoxy-D-Glucose in Combination Therapy. J Breast Cancer. 2012;15:141.

7. den Hoed MAH, Pluijm SMF, te Winkel ML, de Groot-Kruseman HA, Fiocco M, Hoogerbrugge P, et al. Aggravated bone density decline following symptomatic osteonecrosis in children with acute lymphoblastic leukemia. Haematologica. 2015;100:1564-70.

8. Bhojwani D, Pui C-H. Relapsed childhood acute lymphoblastic leukaemia. Lancet Oncol. 2013;14:e205-17.

9. Nguyen K, Devidas M, Cheng S-C, La M, Raetz EA, Carroll WL, et al. Factors influencing survival after relapse from acute lymphoblastic leukemia: a Children's Oncology Group study. Leukemia. 2008;22:2142-50.

10. Li H, Yang BB. Friend or foe: the role of microRNA in chemotherapy resistance. Acta Pharmacol Sin. 2013;34:870-9.

11. Kachalaki S, Ebrahimi M, Mohamed Khosroshahi L, Mohammadinejad S, Baradaran B. Cancer chemoresistance; biochemical and molecular aspects: a brief overview. Eur J Pharm Sci. 2016;89:20-30.

12. Carvalho C, Santos R, Cardoso S, Correia S, Oliveira P, Santos M, et al. Doxorubicin: The Good, the Bad and the Ugly Effect. Curr Med Chem. 2009;16:3267-85.

13. Sugimoto K, Tamayose K, Sasaki M, Hayashi K, Oshimi K. Low-dose doxorubicin-induced necrosis in Jurkat cells and its acceleration and conversion to apoptosis by antioxidants. Br J Haematol. 2002;118:229-38.

14. Miao M, Ji X, Zhang H, Xu J, Zhu H, Shao X. miR-590 promotes cell proliferation and invasion in Tcell acute lymphoblastic leukaemia by inhibiting RB1. Oncotarget. 2016;7:39527-34.

15. Mohammadi A, Mansoori B, Baradaran B. The role of microRNAs in colorectal cancer. Biomed Pharmacother. 2016;84:705-13.

16. Hemmatzadeh M, Mohammadi H, Karimi M, Musavishenas MH, Baradaran B. Differential role of microRNAs in the pathogenesis and treatment of Esophageal cancer. Biomed Pharmacother. 2016;82:509-19.

17. Mavrakis KJ, Van Der Meulen J, Wolfe AL, Liu X, Mets E, Taghon T, et al. A cooperative microRNAtumor suppressor gene network in acute T-cell lymphoblastic leukemia (T-ALL). Nat Genet. 2011;43:673-8.

18. Renou L, Boelle P-Y, Deswarte C, Spicuglia S, Benyoucef A, Calvo J, et al. Homeobox protein TLX3 activates miR-125b expression to promote T-cell acute lymphoblastic leukemia. Blood Adv. 2017;1:733-47. 
19. Wallaert A, Van Loocke W, Hernandez L, Taghon T, Speleman F, Van Vlierberghe P. Comprehensive miRNA expression profiling in human T-cell acute lymphoblastic leukemia by small RNA-sequencing. Sci Rep. 2017;7:7901.

20. Farooqi A, Tabassum S, Ahmad A. MicroRNA-34a: A Versatile Regulator of Myriads of Targets in Different Cancers. Int J Mol Sci. 2017;18:2089.

21. Misso G, Di Martino MT, De Rosa G, Farooqi AA, Lombardi A, Campani V, et al. Mir-34: A New Weapon Against Cancer? Mol Ther -. Nucleic Acids. 2014;3:e195.

22. Zhang L, Liao Y, Tang L. MicroRNA-34 family: a potential tumor suppressor and therapeutic candidate in cancer. J Exp Clin Cancer Res. 2019;38:53.

23. van Beijnum JR, Giovannetti E, Poel D, Nowak-Sliwinska P, Griffioen AW. miRNAs: micro-managers of anticancer combination therapies. Angiogenesis. 2017;20:269-85.

24. Jian C, Tu M-J, Ho PY, Duan Z, Zhang Q, Qiu J-X, et al. Co-targeting of DNA, RNA, and protein molecules provides optimal outcomes for treating osteosarcoma and pulmonary metastasis in spontaneous and experimental metastasis mouse models. Oncotarget. 2017;8:30742-55.

25. Ji Q, Hao X, Zhang M, Tang W, Yang M, Li L, et al. MicroRNA miR-34 Inhibits Human Pancreatic Cancer Tumor-Initiating Cells. Bernhard EJ, editor. PLoS One. 2009;4:e6816.

26. Marques SC, Ranjbar B, Laursen MB, Falgreen S, Bilgrau AE, Bødker JS, et al. High miR-34a expression improves response to doxorubicin in diffuse large B-cell lymphoma. Exp Hematol. 2016;44:238-46.e2.

27. Karrman K, Johansson B. Pediatric T-cell acute lymphoblastic leukemia. Genes Chromosom Cancer. 2017;56:89-116.

28. Marks DI, Rowntree C. Management of adults with T-cell lymphoblastic leukemia. Blood. 2017;129:1134-42.

29. Mansoori B, Mohammadi A, Shirjang S, Baradaran B. Micro-RNAs: The new potential biomarkers in cancer diagnosis, prognosis and cancer therapy. Cell Mol Biol (Noisy-le-grand) [Internet]. 2015;61:110. Available from: http://www.ncbi.nlm.nih.gov/pubmed/26475381.

30. Vera J, Lai X, Schmitz U, Wolkenhauer O. MicroRNA-Regulated Networks: The Perfect Storm for Classical Molecular Biology, the Ideal Scenario for Systems Biology. 2013. p. 55-76.

31. Gerlinger M, Rowan AJ, Horswell S, Larkin J, Endesfelder D, Gronroos E, et al. Intratumor Heterogeneity and Branched Evolution Revealed by Multiregion Sequencing. N Engl J Med. 2012;366:883-92.

32. Ogawa T, Saiki Y, Shiga K, Chen N, Fukushige S, Sunamura M, et al. miR-34a is downregulated in cisdiamminedichloroplatinum treated sinonasal squamous cell carcinoma patients with poor prognosis. Cancer Sci. 2012;103:1737-43.

33. Li X, Ji M, Zhong S, Zha Q, Xu J, Zhao J, et al. MicroRNA-34a Modulates Chemosensitivity of Breast Cancer Cells to Adriamycin by Targeting Notch1. Arch Med Res. 2012;43:514-21. 
34. Wang X, Dong K, Gao P, Long M, Lin F, Weng Y, et al. microRNA-34a Sensitizes Lung Cancer Cell Lines to DDP Treatment Independent of p53 Status. Cancer Biother Radiopharm. 2013;28:45-50.

35. Flanagan L, Meyer M, Fay J, Curry S, Bacon O, Duessmann H, et al. Low levels of Caspase-3 predict favourable response to $5 \mathrm{FU}$-based chemotherapy in advanced colorectal cancer: Caspase-3 inhibition as a therapeutic approach. Cell Death Dis. 2016;7:e2087-7.

36. Végran F, Boidot R, Oudin C, Riedinger J-M, Bonnetain F, Lizard-Nacol S. Overexpression of Caspase3s Splice Variant in Locally Advanced Breast Carcinoma Is Associated with Poor Response to Neoadjuvant Chemotherapy. Clin Cancer Res. 2006;12:5794-800.

37. Anagnostou VK, Lowery FJ, Zolota V, Tzelepi V, Gopinath A, Liceaga C, et al. High expression of BCL-2 predicts favorable outcome in non-small cell lung cancer patients with non squamous histology. BMC Cancer. 2010;10:186.

38. Lamers F, Schild L, den Hartog IJM, Ebus ME, Westerhout EM, Ora I, et al. Targeted BCL2 inhibition effectively inhibits neuroblastoma tumour growth. Eur J Cancer. 2012;48:3093-103.

39. Kastenhuber ER, Lowe SW. Putting p53 in Context. Cell. 2017;170:1062-78.

40. Zenz T, Mohr J, Eldering E, Kater AP, Bühler A, Kienle D, et al. miR-34a as part of the resistance network in chronic lymphocytic leukemia. Blood. 2009;113:3801-8.

41. Mraz M, Malinova K, Kotaskova J, Pavlova S, Tichy B, Malcikova J, et al. miR-34a, miR-29c and miR17-5p are downregulated in CLL patients with TP53 abnormalities. Leukemia. 2009;23:1159-63.

\section{Figures}

\section{A}

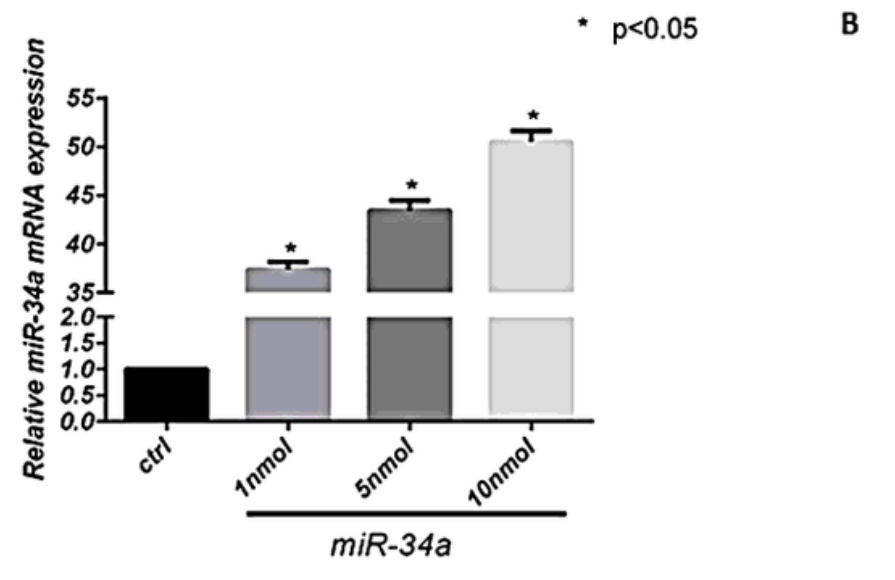

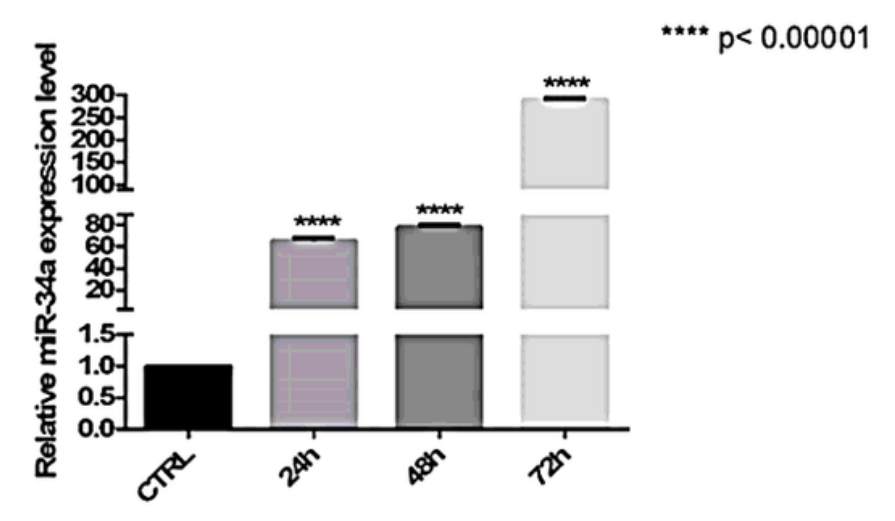


Figure 1

Transfection of miR-34a restored the expression of miR-34a in Jurkat cells. Cells were transfected with miR-34a and the expression of microRNA was investigated using qRT-PCR method. The results revealed that after miR-34a transfection, the miR-34a expression was remarkably increased compared to the control. (A) The expression of miR-34a in different concentrations $(P<0.05)$. (B) The expression of miR$34 \mathrm{a}$ (at the concentration of $5 \mathrm{nmol}$ ) at different times $(P<0.00001)$. Results are expressed as mean $\pm S D$ of three independent experiments.
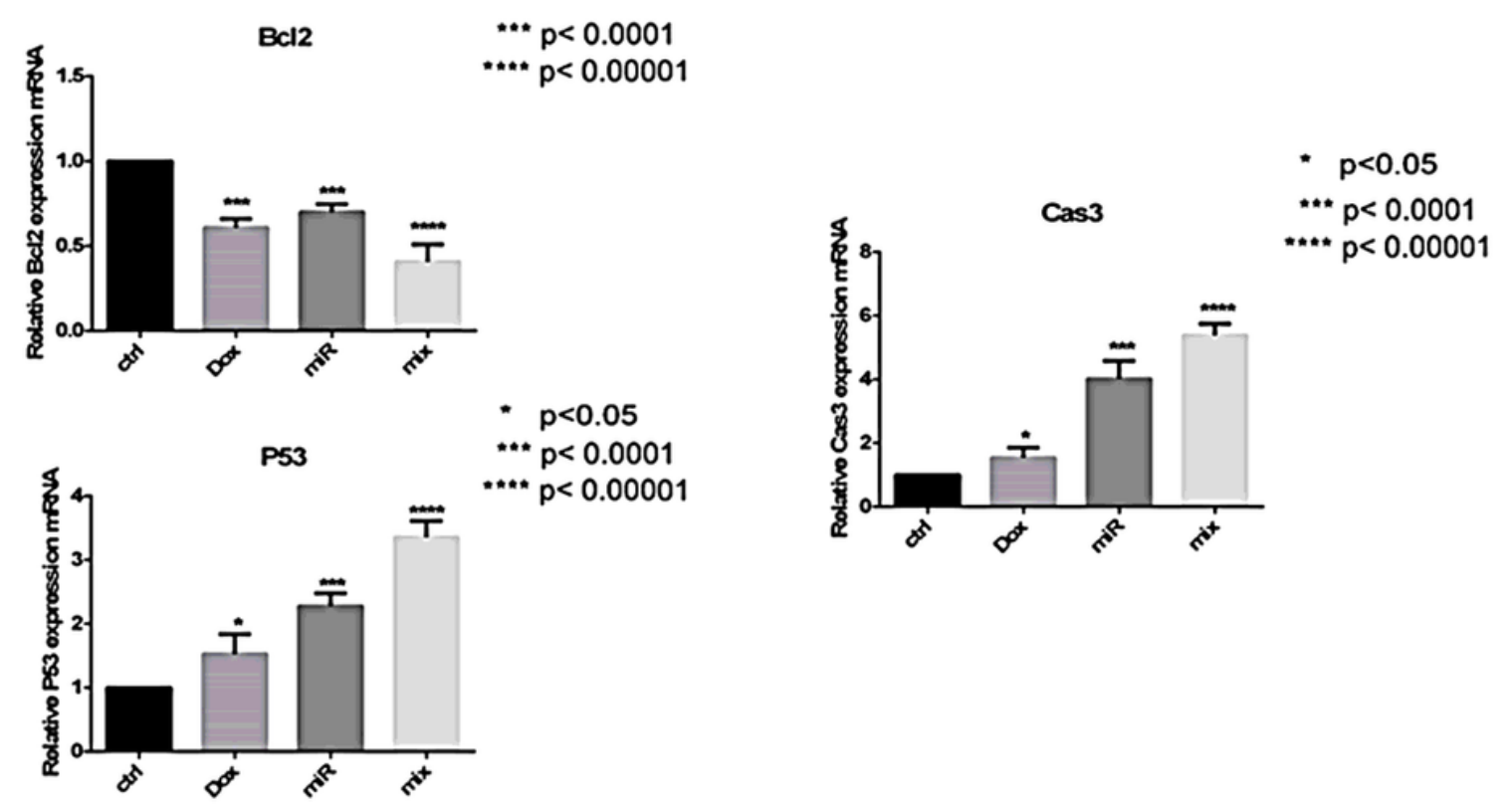

\section{Figure 2}

The effect of miR-34a transfection and treatment with doxorubicin on the expression quantities of the $\mathrm{Bcl}-2$, the target gene of miR-34a. The expression of Caspase-3 and p53genes in the cells treated with combination of miR-34a and doxorubicin drug was increased compared to the control group. In addition, the expression of the Bcl-2 gene in the cells treated with combination of miR-34a and doxorubicin drug was decreased compared to the control group. Results are expressed as mean \pm SD of three independent experiments. 

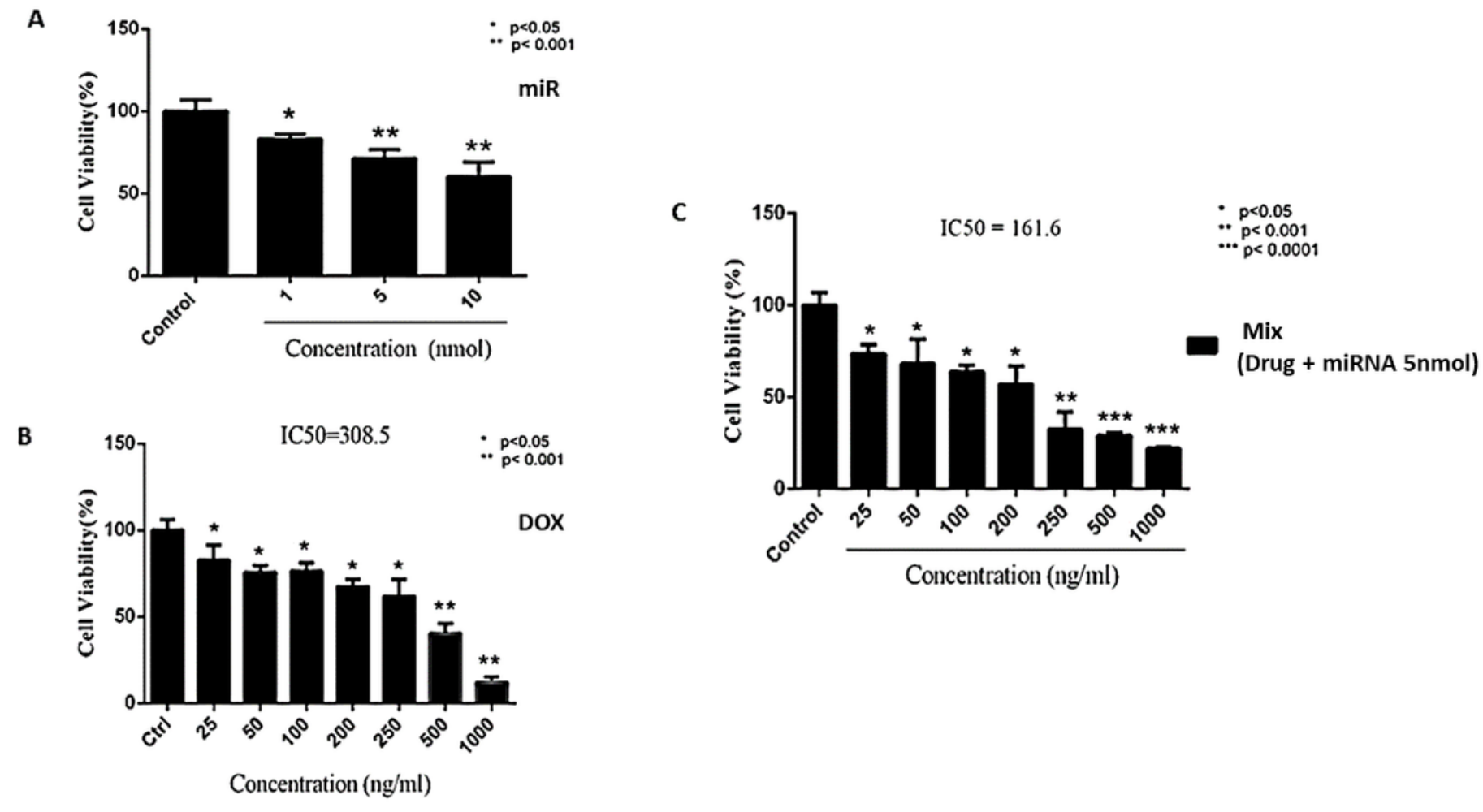

\section{Figure 3}

The effect of miR-34a transfection and treatment with doxorubicin on Jurkat cells viability using MTT assay. (A) The survival rate in cells transfected with miR-34a alone was reduced compared to the control group. (B) The survival rate in cells treated with different doses of doxorubicin was reduced compared to the control group, $(\mathrm{IC50}=308.5 \mathrm{ng} / \mathrm{ml})$. (C) The survival rate in cells treated with combination of miR-34a and doxorubicin drug was significantly reduced compared to the control group. Results are expressed as mean \pm SD of three independent experiments. 

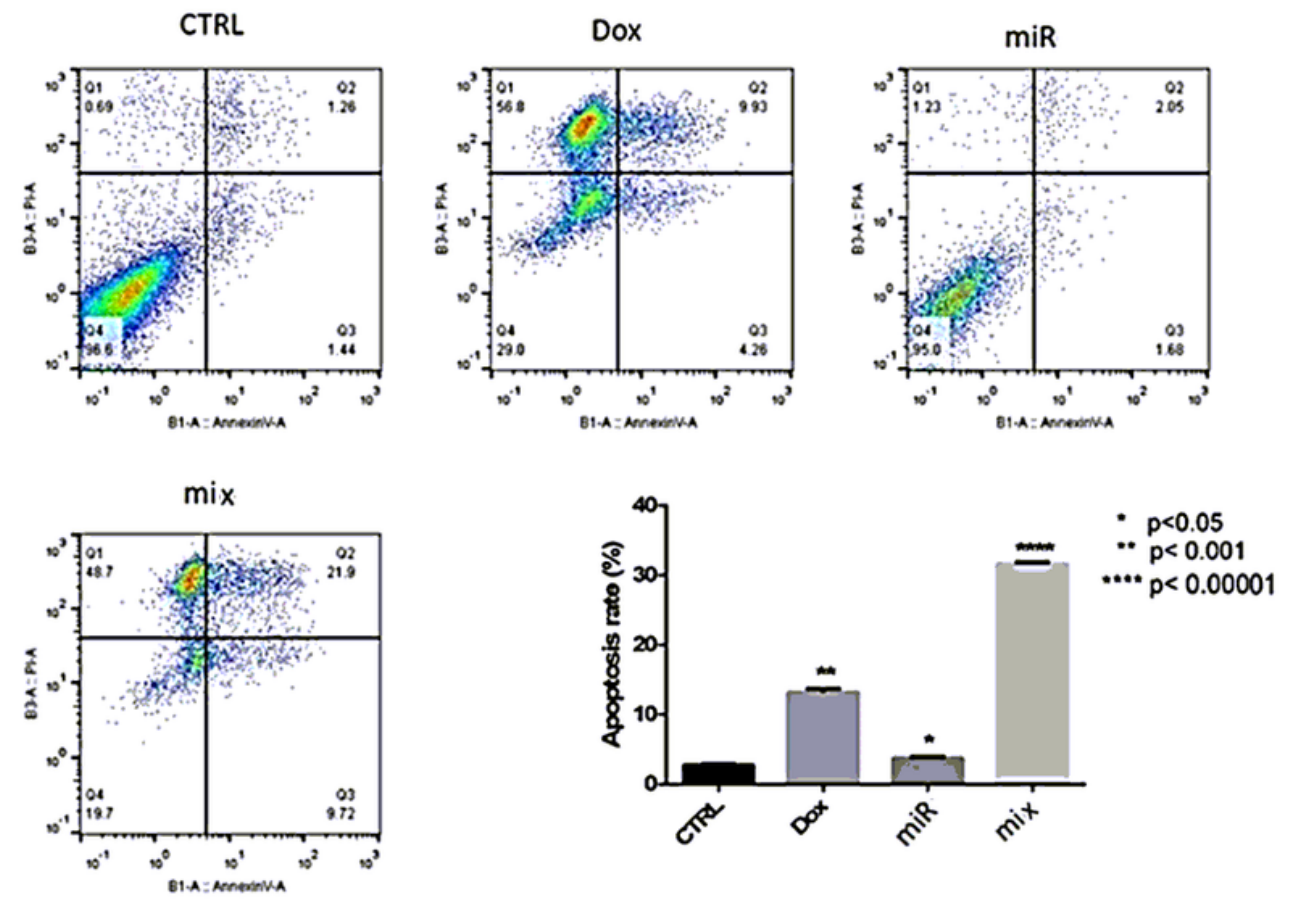

\section{Figure 4}

Apoptosis analysis in Jurkat cells using flow cytometry. As shown there is a considerable increase in the number of apoptotic cells in the combination of miR-34a and doxorubicin compared to the control group. Results are displayed as mean \pm SD $(P<0.00001)$ of three independent experiments. 

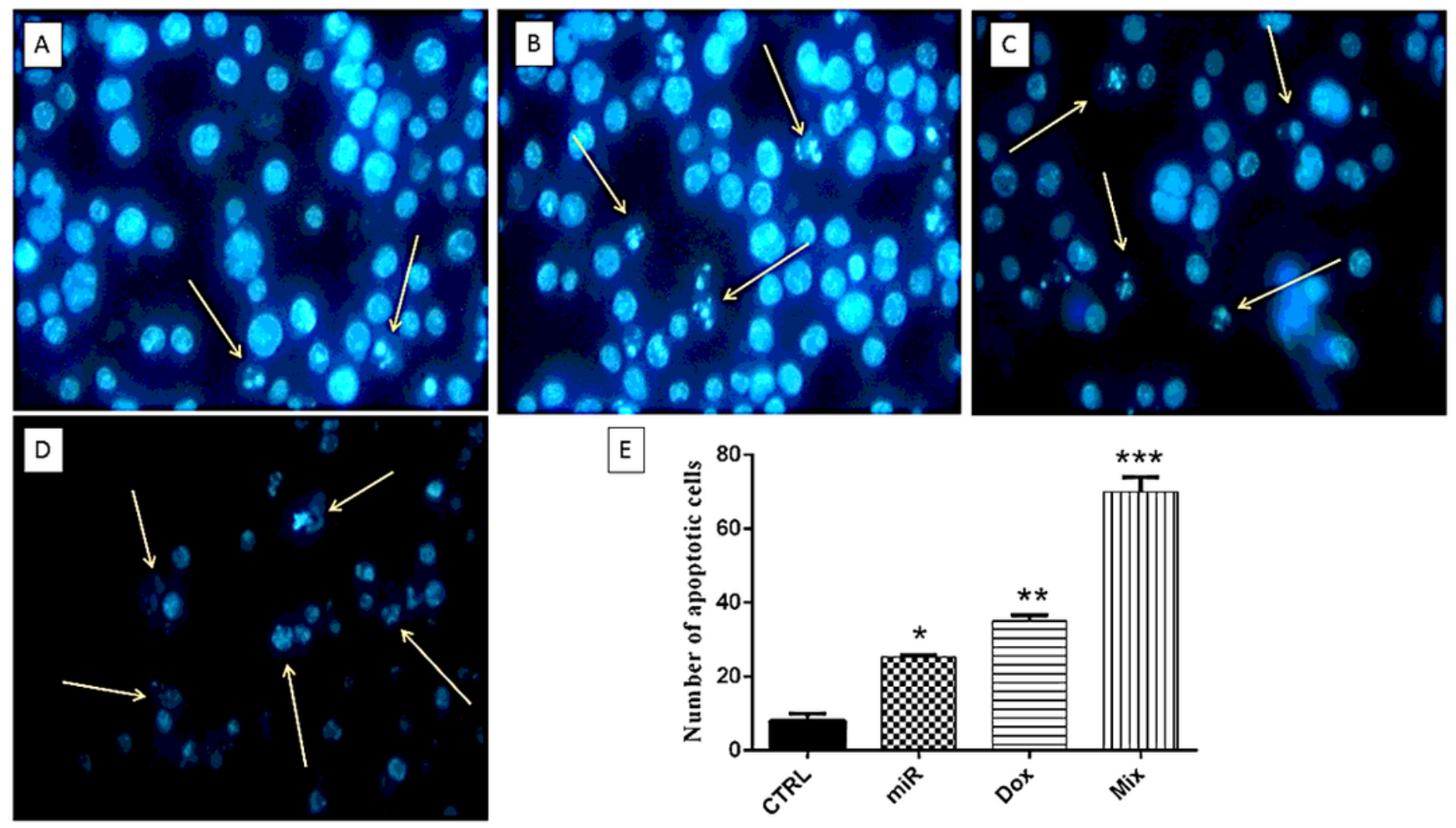

\section{Figure 5}

Detection of apoptosis and nuclear fragmentation during the apoptosis using DAPI staining method. The arrow represents fragmented and deformed nucleus in the cells after the treatment. A) Control group; B) transfected with miR-34a; C) treated with an IC50 dose of doxorubicin; and D) treated with the combined miR-34a and doxorubicin drug. The apoptosis rate in cells that were treated with the combined miR$34 \mathrm{a} /$ doxorubicin drug was considerably increased compared to the control group. (*P value $<0.05, * \star P$ value $<0.01, \star \star \star P$ value $<0.001)$. Results are displayed as mean $\pm S D$ of three independent experiments. 

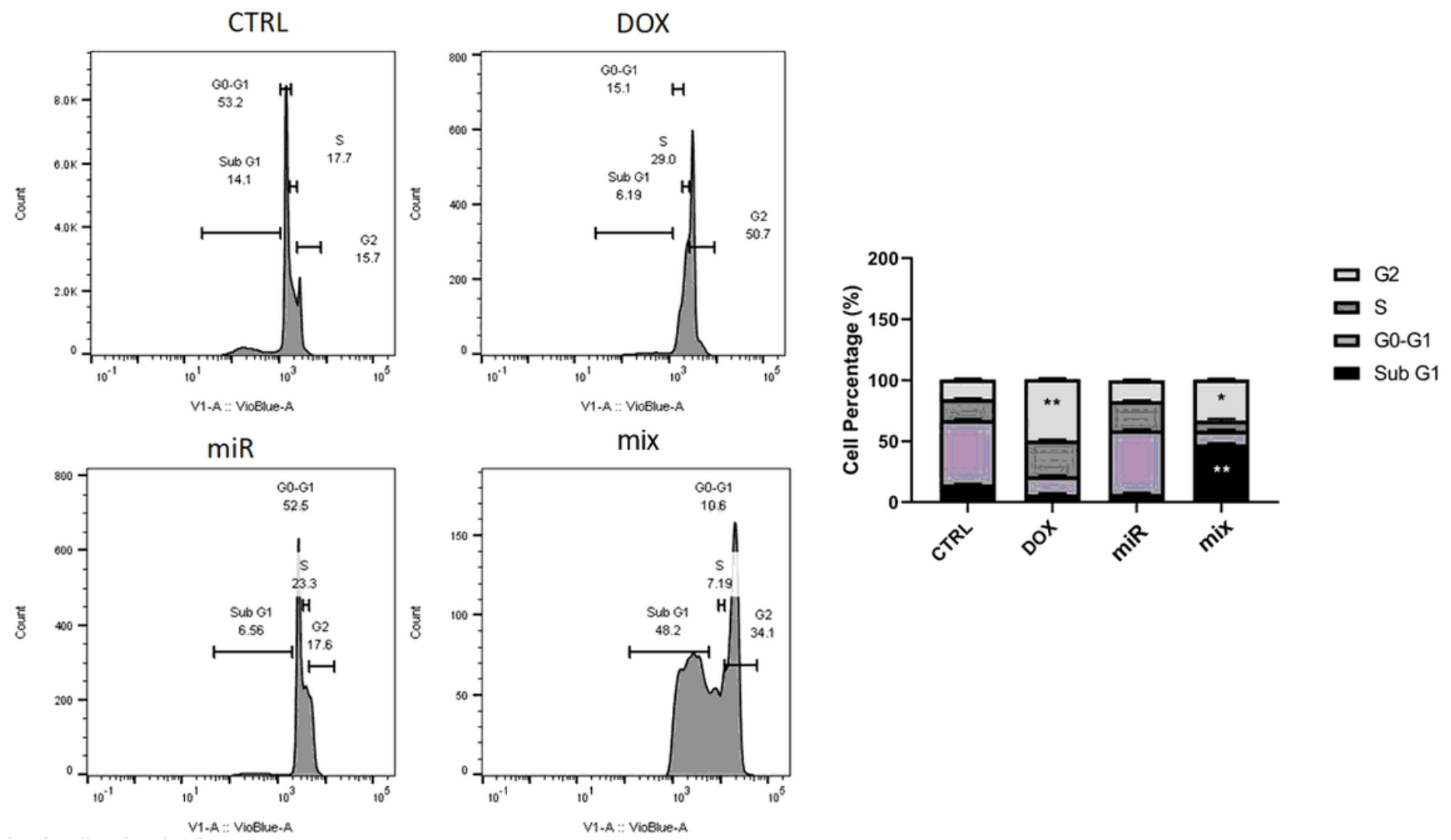

\section{Figure 6}

Cell cycle analysis in the Jurkat cells using flow cytometry. Seventy-two hours after treatment with miR34a, doxorubicin, and miR-34a/doxorubicin, Jurkat cells treated with DAPI dye and cell cycle results was assessed using flow cytometry. In the combined miR-34a/doxorubicin, the cell cycle arrest has occurred in sub G1 (**P value $<0.01$ ) and G2 (*P value $<0.05$ ) phases compared to the control group. Results are expressed as mean $\pm \mathrm{SD}$ of three independent experiments. 